\title{
Emergence of Business Value from Complementary Interactions between Informational and Transactional IT systems
}

\author{
Ida Asadi Someh \\ Department of Computing and Information Systems, \\ The University of Melbourne \\ ida.asadi@unimelb.edu.au

\section{Graeme Shanks} \\ Department of Computing and Information Systems, \\ The University of Melbourne \\ gshanks@unimelb.edu.au
}

\begin{abstract}
Different IT asset classes generate business value consistent with the strategic goal of that asset class. While transactional IT systems contribute to process efficiencies, informational IT systems generate insights and contribute to informational benefits. We argue that the complementary interactions between these two classes of IT systems can support both informed and efficient processes and lead to greater business value. We use systems theory to develop a research model, which includes the complementary interactions between transactional and informational IT systems and the emergence of higher-order IT-enabled business systems. The two IT systems interact and augment other business systems to create higher-order emergent IT-enabled business systems. Emergent IT-enabled business systems lead to transactional, informational and strategic benefits. The paper concludes by calling for empirical studies that focus on the complementary relations between transactional and informational IT systems and their impact on business value.
\end{abstract}

Keywords: Informational IT systems; Transactional IT systems; Systems theory; Emergence; Business value

\section{Introduction}

Information systems researchers have sought to understand the Business Value of Information Technology (BVIT) resources for more than two decades. This research has resulted in a diverse literature in terms of IT characterisation, theories applied and the analytical and methodological approaches employed for empirical assessment. Despite advancements in BVIT research, particularly in conceptualising IT resources and business value, further research on the BVIT resources and their complementary interactions with other business resources is strongly encouraged (Kohli 2008). In this paper, we address two important gaps in the BVIT literature.

First, current research on the relationship between IT and business value examines the business impacts of one class of IT (Aral and Weill 2007), in isolation from other classes of IT. Researchers have explored the business value of IT infrastructure (e.g. computers, email and networks) (Broadbent et al. 1999), transactional IT resources (e.g. automated systems) (Weill 1992), and informational resources (e.g. business intelligence and information management systems) (Elbashir et al. 2008; Mithas et al. 2011). However, there is insufficient understanding of the complementary interactions between different classes of IT resources in generating IT-based business value. Particularly, the interactions between Transactional and Informational IT resources still remain unexplored. Transactional IT resources standardise and automate organisational processes to cut costs and increase efficiencies (Aral and Weill 2007). Informational IT resources process organisational data and provide business processes and decision-makers with required information and insights (Davenport and Harris 2007). We 
focus on these two classes of IT resources and seek to understand how they can interact to develop higher-order IT-enabled business resources.

Second, informational IT resources (Aral and Weill 2007) such as Business Analytics (BA) systems and Business Intelligence (BI) systems have recently topped the list of technology priorities for CIO's (Hagerty et al. 2012). Informational IT resources collect, store and analyse organisational data and provide organisational decision-makers with meaningful information and insights at multiple levels of an organisation (Davenport and Harris 2007; LaValle and Lesser 2013). Although several industry-based reports and academic research have provided evidence for the business value of informational IT systems (Davenport and Harris 2007; Davenport et al. 2010; Isik et al. 2011; Shanks and Bekmamedova 2012; Sharma et al. 2010; Wixom and Watson 2001; Wixom et al. 2013), there is still little theoretical understanding of how these systems create business value and improve firm performance. Therefore, we also seek to develop a theory that explains the complementary interactions between informational and transactional IT resources as a mechanism for business value generation. Based on these two research gaps, we ask the following research question:

How do informational and transactional IT resources complement each other in generating IT-based business value?

To answer this research question, we use systems theory and the concept of emergence to develop a research model that explains how informational and transactional IT systems interact with each other to augment other business systems and develop emergent IT-enabled business systems. The emergent IT-enabled business systems include complementary interactions (or emergent properties) between transactional and informational IT systems. The emergent properties include competitive actions of business people based on analytical insights. The competitive actions are both informed and effective and efficient. The emergent IT-enabled business systems are capable of creating significant business value.

We explore the research question using examples from Customer Relationship Management (CRM). CRM involves managing customer processes and interactions in sales, marketing and services (Buttle 2004). IT assets and capabilities have a significant impact on the quality of interactions with customers (Ray et al. 2005). Particularly, informational IT systems have been widely used in CRM and have provided CRM peopleand processes with insights from customer value analysis, customer behavior analysis and customer segmentation (Goodhue et al. 2002). Transactional IT systems such as sales force systems have also standardised and automated many customer-facing processes (Buttle 2004). Therefore, CRM is a suitable context to study the complementary interactions between informational and transactional IT systems and the emergent IT-enabled CRM systems.

Our motivations for this paper are two-fold. First, research on BVIT has shown mixed results for the relationship between IT investments and business value (Chae et al. 2014). Despite these mixed results concerning business value, IT has become an integral part of every business, and organisations are investing more on advanced information systems to operate, innovate and gain competitive advantage over their rivals (Mithas et al. 2012). Therefore, there is a clear need for further examination of the business value of IT. Second, industry reports and case studies have highlighted the significance of informational IT systems such as BA systems to managers (Chen et al. 2012; Davenport and Harris 2007). BA systems were identified as one of the four major technology trends in 2012 (IBM 2013). Developing a useful theory that explains the interactions of informational IT systems with other IT systems such as transactional IT systems in generating business value is an important direction of research.

The paper is organised as follows. First, we discuss the theoretical background to the research and highlight important research themes that emerge from the BVIT literature. Second, we introduce systems theory and emergence as the main theoretical underpinning for understanding the complementary interactions between transactional and informational IT systems and emergence of IT-enabled business systems. Third, we discuss emergent ITenabled business systems including the complementary interactions between transactional and informational IT systems. Following that we present the research model, and provide 
definitions for the constructs and hypotheses in the model. We then discuss the contributions to knowledge of the study, its implications for researchers and practitioners, limitations and future research and conclude the paper.

\section{Business Value of IT}

Understanding the relationship between IT and business value has long been of interest to information system researchers. Early research was unable to demonstrate that investments in IT provided business value, with some arguing that IT is a commodity and not associated with strategic value (Brynjolfsson 1993; Carr 2003; Lucas 1999). Since then researchers have used RBV theory to examine the business value of IT using the constructs of IT investment, resources and capabilities. The RBV theory argues that sustainable competitive advantage is the result of organisational resources that are valuable, rare, difficult to imitate and nonsubstitutable (VRIN properties) (Barney 1991; Penrose 1995). Although RBV theory has been successful in linking IT resources to business value, studies in this area still show mixed results for the direct relationship between IT and business value. Bharadwaj (2000) and Santhanam \& Hartono (2003) reported a significant superior performance for organisations with betterquality overall IT capabilities. However, Chae et al. (2014) replicated the study and did not find support for the same hypotheses in following years, concluding the relationship may not exist. Another body of literature examined the impact of overall IT investment on firm performance. While Aral and Weill (2007) found no significant variations in firm performance attributed to overall IT investment, a recent study reported a significant positive relationship between total IT investment and firm profitability (Mithas et al. 2012). We argue that establishing a direct link between overall IT investments, capabilities and resources and business value has not provided convincing insights into how IT influences organisational processes and consequently organisational performance. Therefore, we identify four themes in the literature that help understand the mechanisms of IT-based business value generation.

\subsection{Research Themes from BVIT Literature}

Four research themes that are important in conceptualising the IT construct and examining IT-based business value are: (1) IT capabilities complement IT assets in creating IT-based business value; (2) IT asset classes generate value consistent with their strategic goals; (3) IT resources indirectly influence business value (via IT-enabled business resources); and (4) business value from IT resources is contingent on other organisational variables. The four themes are discussed below.

\section{Research theme 1: IT Capabilities Complement IT Assets in Creating IT Business Value}

IT assets are the technologies that organisations invest in to enable their IT based capability. They include hardware, software and data. IT capabilities are interlocking systems of competencies (including IT skills and IT management) and practices (including IT processes and routines and the culture of IT use) (Aral and Weill 2007). IT assets and capabilities together are associated with greater business value than conceptualising IT as assets or capabilities separately (Aral and Weill 2007). IT assets and capabilities together comprise the IT resources in an organisation (Aral and Weill 2007). This is because organisational IT capabilities complement and reinforce the impact of IT assets on firm performance (Aral and Weill 2007). Since investing in IT and acquiring IT assets has become a competitive necessity for organisations, IT assets and investment are not likely to explain the variance in business value (Ray et al. 2005). However, firm-specific and unique IT capabilities developed over time and embedded in organisational processes, reinforce the impact of IT assets on business value (Bharadwaj 2000b). For example, human IT resources complement technological IT resources in creating business value (Melville et al. 2004). The increased complementarity of combined IT assets and capabilities is associated with increased business value per dollar investment (Aral \&Weill 2007; Melville et al. 2004).

\section{Research Stream 2: IT Asset Classes Generate Value Consistent with Their Strategic Goal}


Different IT asset classes generate business value consistent with the strategic goal of the asset (Aral and Weill 2007). IT asset classes include Infrastructure, Transactional, Informational and Strategic (Weill 1992). Infrastructure assets are the shared IT resources utilised across organisations such as servers, networks, laptops and databases. Transactional IT assets standardise and automate organisational operations to cut costs or increase efficiency for the same cost. Examples of transactional IT resources include operational CRM resources and Supply Chain Management (SCM) resources. Informational IT assets provide information for purposes such as accounting, sales, compliance and communication. Examples include decision support, BI and BA systems. These systems support effective decision-making and enable profitable operations. Strategic IT resources help organisations achieve competitive advantage by supporting entry into new markets or by helping to develop new products, services or business processes (such as mobile banking in the finance sector). Each of these asset classes will contribute to business value consistent with the strategic goal of that class. For instance, transactional IT investments contribute to reduced costs while investments in informational IT assets influence profitability (Aral and Weill 2007).

\section{Research stream 3: IT Resources Indirectly Influence Business Value}

The third research theme suggests that IT resources positively and indirectly influence business value (Bharadwaj 2000a; Elbashir et al. 2008; Melville et al. 2004; Mithas et al. 2011; Pang et al. 2014; Pavlou and El Sawy 2006; Tanriverdi 2005). The indirect influence is through the intermediate contribution of IT resources to other business resources. IT resources are deployed to enhance the capabilities and business processes. IT and other business capabilities together may beconceptualised as higher-order IT-enabled business capabilities, which in turn influence firm performance (Bharadwaj 2000). However, the first-order effect of IT on business capabilities is also important.

Research Stream 4: Business Value from IT Resources is Contingent on other Organisational Variables

The fourth research theme provides evidence that achieving value from IT investments is contingent on other organisational variables (Melville et al. 2004; Ray et al. 2005; Weill 1992). This theme is based on contingency theory which attempts to understand the interrelationships within and among organisational subsystems as well as between the organisation and its environment under varying conditions (Kast and Rosenzweig 1981; Weill and Olson 1989). The contingency approach suggests that a number of variables mediate or moderate the relationship between IT and business value. For example, shared knowledge between IT managers and line managers moderates the relationship between IT and customer service performance (Ray et al. 2005). The complementarity of other organisational capabilities (such as management quality and the culture of IT use) to IT investments is another contingency variable that will moderate the relationship between IT and business value (Melville et al. 2004; Aral and Weill 2007). Nevo and Wade (2011) argue that the business value of IT assets is contingent upon their ability to form synergistic interactions with other organisational resources.

We draw on these four research themes to conceptualise our understanding of the value of transactional and informational IT resources implemented in customer processes.

\section{Systems Theory and Emergence}

Systems theory deals with systems taken as a whole, rather than individual parts (Ackoff 1971). A system is a composite thing comprising a number of parts (subsystems), which interact to accomplish a set of goals. The interactions among parts constitute a whole, which is greater than the sum of the individual parts. The whole system, derived from the synergistic interaction of the parts equals the sum of its parts plus their complementary interactions (Ackoff 1971). However, it is very complex to model exactly how subsystems interact to constitute a whole. Rules and laws can never be used to explain the evolution of a system, as there are a large number of options and associated decisions at each point in the system's 
evolution (Corning 2002). However, the properties, patterns and structure that emerge from the interactions are an effective way of studying the whole. The new properties derived from the subsystem's interactions are called emergent properties. The emergent properties of a collective system are the things that can be perceived and measured (Corning 2002). Emergent properties can be positive, neutral or negative according to organisational goals. Positive emergent properties are called synergy (Nevo and Wade 2010). Synergy between IT and other organisational resources is realised when IT and other organisational resources are compatible and integrated (Nevo and Wade 2010). Compatibility refers to the degree to which systems fit with each other and is achieved when systems are able to seamlessly work together. Compatibility between transactional and informational systems ensures that transactional systems (people and processes) are able to work with informational tools, functionalities and insights. Conversely, the informational tools should match the decision needs of the transactional system, as different organisational resources may have different information needs (Isik et al. 2011). Integration effort refers to the effort of management to bring transactional and informational resources together and direct and support their interaction congruent with organizational goals (Nevo and Wade 2010). Management is responsible for managing the changes and properly accommodating informational resources in relationships with transactional resources.

An organisation, with respect to systems theory, can be conceptualised as a set of interconnected systems (Kast and Rosenzweig 1981). This contrasts with the RBV, which views an organisation as a bundle of resources (Barney 1991). The use of systems theory helps to model the interaction among resources, which is not possible using RBV theory. A system from the systems theory perspective corresponds to a bundle of resources from RBV theory. Therefore, a system in our study refers to combination of assets and capabilities (Aral and Weill 2007).

\section{Emergence of IT-Enabled Business Systems}

Our argument is that transactional and informational IT systems directly interact with other business systems and transform them to higher-order IT-enabled business systems with emergent properties. While transactional IT systems contribute to process efficiencies, informational IT systems generate insights and contribute to informational benefits within the processes of other business systems. More importantly, the two IT systems interact and complement each other when developing the higher-order IT-enabled business systems. Complementarity is the main source of synergy and the emergence of new properties within the business system (Nevo and Wade 2010; Tanriverdi 2006). The emergent IT-enabled business system supports informed and intelligent, as well as effective and efficient processes. Figure 1 represents the properties of informational and transactional systems and emergent properties arising from their complementary interactions.

Transactional and informational IT systems complement each other in several ways. The use of transactional IT systems enables new IT-based business opportunities for organisations including the implementation of informational IT systems. The huge amount of data generated from transactional IT systems has led to the emergence of advanced informational IT systems to take advantage of the organisational data and provide insights for organisational processes. Organisations collect extensive amounts of data using their transactional IT systems about their customers, internal processes and suppliers. This data is managed, analysed and used for reporting purposes. Although transactional IT systems support limited analytics and reporting using operational data, advanced analysis of organisational data and the generation of insights require a different set of systems and skills. Informational IT systems offer sophisticated analysis, reporting and visualisation of organisational data. The advanced informational IT systems would not exist without the transactional IT systems and the data collected from organisational processes using these systems. 


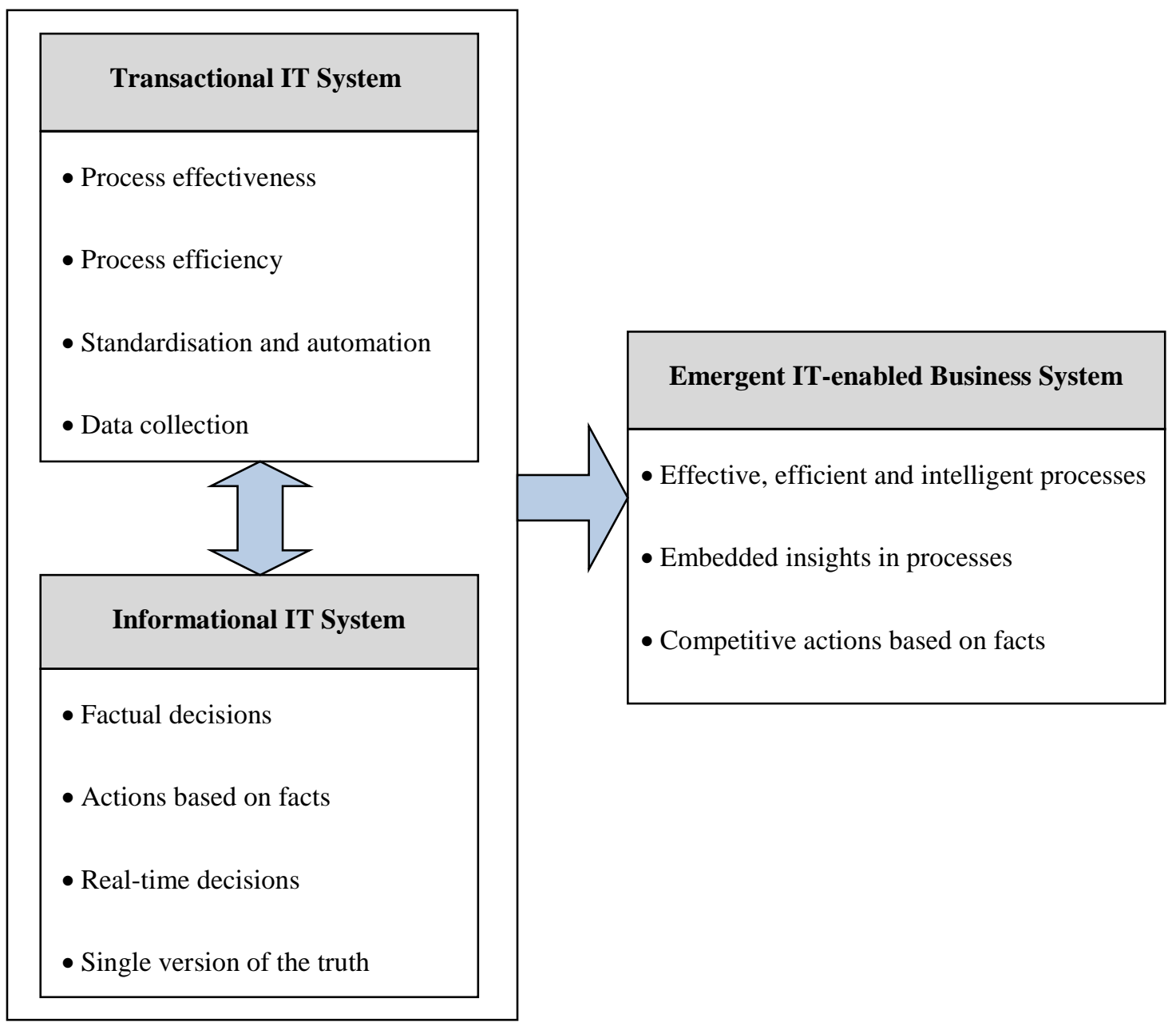

Figure 1. Complementary Interactions between Transactional and Informational IT Systems

Informational IT systems analyse organisational data and enhance organisational processes and their transactional systems by supplying meaningful information and insights to decisionmaking processes. The enhanced transactional systems enable organisations to take competitive actions leveraging insights from the informational system and promote fact-based decisions. Transactional IT systems reinforce the impact of informational systems by automating and embedding insights into their operational processes. Insights from informational IT systems would not be exploited and frequently used unless they were automated and embedded within transactional systems. Transactional IT systems help re engineer business processes and develop efficient and also intelligent processes. The new insights embedded in transactional systems will subsequently generate a new source of data for informational systems to analyse, provide feedback and propose new initiatives. Hence, transactional and informational IT systems are interdependent and complement and reinforce each other in practice. These complementary interactions between IT systems can be a significant source of IT-based business value.

Historically, transactional IT systems were implemented in CRM processes to reduce the costs of customer-facing processes in sales, marketing and service areas (Buttle 2004). This was particularly evident in the trend towards call-centre and contact-centre operations where sales and service processes were re-engineered. Process reengineering based on CRM workflows meant that managers had better reporting and control (Buttle 2004). Transactional IT systems generated large amounts of customer-related data. As companies began to build more complete customer-related databases, based on customer purchases, service enquiries and so 
on, it became possible to overlay informational IT systems. Transactional IT systems generated much of the data that analytical systems began to exploit for cross selling, up selling and churn prediction in particular (Buttle 2004). Analytical CRM is enabled by the data generated by transactional IT systems, together with other external data obtained from third parties. The insights from informational IT systems improve decision-making in operational processes. Aral and Weill (2007) explain this complementary interaction of informational and transactional IT systems using the 7-Eleven J apanese case study. 7-Eleven used transactional IT to process 35 million sales transactions and 5 million order transactions per day and extracted the relevant data for its informational systems. The data were integrated, analysed and injected back into operational processes. Store workers leveraged the insights to take actions and increase sales and profitability. These actions were supported by both transactional and informational IT systems and their complementary interactions.

\section{Proposed Research Model}

The research model, presented in Figure 2, explains how the quality of transactional and informational IT systems and their complementary interactions can generate business value. The locus of IT value generation is a business system such as a CRM system. A business system comprises business assets and capabilities. For example, a CRM system refers to the combination of business people (e.g. marketers and sales people) and processes (e.g lead generation and campaign management). The goal of the transactional and informational IT systems is to extend the capabilities of the business system. We use a systems approach (Burton-J ones et al. 2014) to develop the research model, proposing that the two IT systems interact and complement each other to augment other business systems and develop the emergent IT-enabled business system. Informational and transactional IT systems are associated with transactional and informational benefits, respectively. However, the emergent IT-enabled business system is a higher-order business system with new properties and will influence strategic measures of business value. The definitions of constructs in the model are provided below and summarised in Table 1. The hypotheses follow.

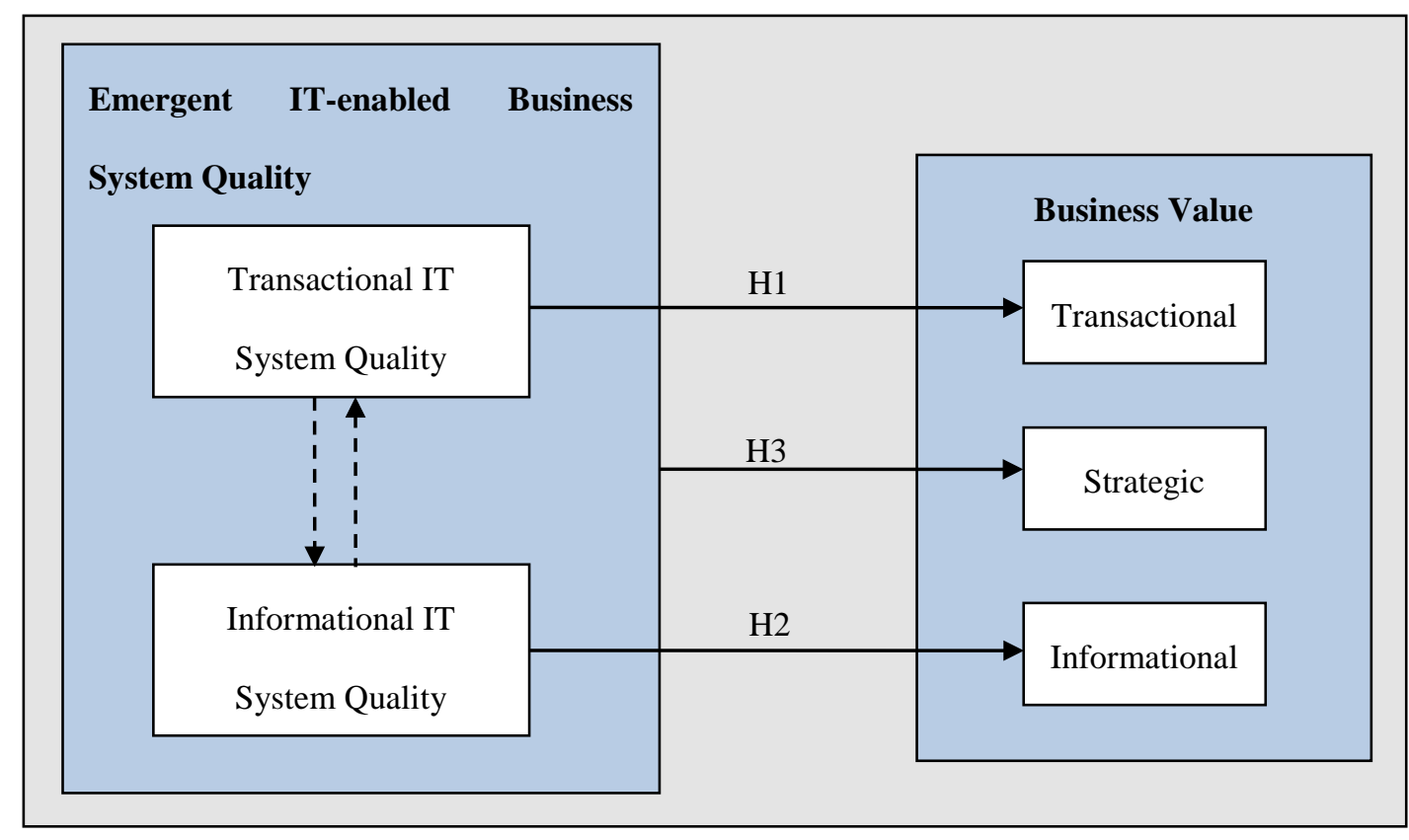

Figure 2. Research Model

\subsection{Construct Definitions}

Detailed definitions of the constructs in the research model are provided below. 


\subsubsection{Transactional IT System Quality}

Transactional IT System Quality refers to the degree to which transactional IT systems are successful in standardising and automating organisational processes (Weill 1992). The organisational goal of transactional IT systems is to reduce the cost of transacting with customers through achieving efficiency and effectiveness (Aral and Weill 2007).

\begin{tabular}{|c|c|c|}
\hline Construct & Definition & Reference \\
\hline $\begin{array}{l}\text { Transactional IT } \\
\text { System Quality }\end{array}$ & $\begin{array}{l}\text { The degree to which transactional IT systems are effective in } \\
\text { standardising and automating organisational processes. }\end{array}$ & $\begin{array}{l}\text { (Buttle 2004; } \\
\text { Iriana and Buttle } \\
\text { 2006) }\end{array}$ \\
\hline $\begin{array}{l}\text { Informational IT } \\
\text { System Quality }\end{array}$ & $\begin{array}{l}\text { The degree to which informational IT systems are effective } \\
\text { in storing, analysing, reporting and generating insights from } \\
\text { organisational data. }\end{array}$ & $\begin{array}{l}\text { (Davenport } \text { and } \\
\text { Harris 2007) }\end{array}$ \\
\hline $\begin{array}{l}\text { Emergent IT- } \\
\text { enabled } \\
\text { Business System } \\
\text { Quality }\end{array}$ & $\begin{array}{l}\text { The degree to which a business people can effectively } \\
\text { leverage analytical insights provided by informational IT } \\
\text { systems and embedded in the transactional IT systems }\end{array}$ & $\begin{array}{l}\text { (Buttle 2004; } \\
\text { Iriana and Buttle } \\
\text { 2006) }\end{array}$ \\
\hline Business Value & $\begin{array}{l}\text { Business value that is generated from the use of Emergent } \\
\text { IT-enabled Business Systems. Business Value has three } \\
\text { dimensions including, Transactional, Informational and } \\
\text { Strategic benefits. } \\
\text { Transactional benefits include process efficiencies, } \\
\text { effectiveness and cost reduction. } \\
\text { Informational benefits include fact-based decision making, } \\
\text { real-time decisions, single version of the truth and actions } \\
\text { based on facts. } \\
\text { Strategic benefits include time to market, increased revenue } \\
\text { and superior customer experience. }\end{array}$ & $\begin{array}{l}\text { (Aral and Weill } \\
\text { 2007; Coltman } \\
\text { 2007; Wixom et } \\
\text { al. 2013) }\end{array}$ \\
\hline
\end{tabular}

Table 1. Definition of Constructs in the Research Model

Transactional IT systems include transactional assets and capabilities. Transactional assets include standard workflow and automation tools, software packages from IT vendors such as SAP and in-house software technologies to design and develop automated systems. The transactional capabilities include the human IT skills in business analysis, developing IT applications and integrating them with existing applications. They include the ability of business analysts to identify inefficiencies and propose optimised solutions for organisational processes. They also include the ability of the transactional IT staff to customise off-the-shelf vendor applications to address business needs. Transactional assets and capabilities interact to standardise and automate customer-facing processes in marketing, sales and service (Buttle 2004; Iriana and Buttle 2006).

\subsubsection{Informational IT System Quality}

Informational IT System Quality refers to the degree to which IT systems are successful in storing, analysing, reporting and interpreting high quality data (Davenport and Harris 2007). The organisational goal of Informational IT systems (Aral and Weill 2007) is to provide the right information to the right people at the right time (Davenport and Harris 2007).

Informational IT systems are composed of assets and capabilities. Informational assets are the technologies that organisations invest in to enable their information-based analytical capability. Informational assets include data warehouses, Extract Transform \& Load (ETL) tools, analytical software packages from IT vendors such as IBM COGNOS, Oracle's OBIEE, data mining tools, Online Analytical Processing (OLAP), digital dashboards, and high-quality data (Shanks and Bekmamedova 2012). Informational capabilities include analytical human skills to analyse and generate insights from data (analytical professionals and data scientists), management quality in planning, implementing and measuring initiatives, analytical 
processes and routines and analytical culture in the organisation (Shanks and Bekmamedova 2012).

\subsubsection{Emergent IT-enabled Business System Quality}

Emergent IT-enabled Business System Quality refers to the degree to which the IT-enabled business system is able to leverage analytical insights provided by the informational system and embedded in the transactional system. In the case of unstructured decisions, emergent ITenabled business systems may directly use the insights from informational systems (without using transactional systems). The emergent IT-enabled business system comprises informational IT and transactional IT systems and its quality depends on the quality of the emergent properties arising from the interaction between its components.

\subsubsection{Business Value}

Business Value is generated from the use of emergent IT-enabled business systems. Emergent IT-enabled business systems include informational IT and transactional IT systems and their complementary interactions. Emergent IT-enabled business systems will generate transactional, informational and strategic benefits. Transactional Benefits include process efficiencies, effectiveness and cost reduction (Aral and Weill 2007) and are generated as a result of using transactional IT systems within emergent IT-enabled business systems. Informational IT systems create Informational Benefits. Informational Benefits include factbased decision making, real-time decisions, single version of the truth and actions based on facts (Wixom et al. 2013). Strategic Benefits include time to market, increased revenue and superior customer experience (Coltman 2007; Wixom et al. 2013). The strategic benefits are created from the emergent properties arising from the interaction between transactional IT and informational IT systems within other business systems. The business value is perceived at the process-level (Melville et al. 2004).

\subsection{Hypotheses Development (Hypotheses 1-3)}

The hypotheses associated with the research model are explained below.

Transactional IT systems standardise and automate organisational processes to achieve effectiveness and efficiency and reduce the cost of organisational processes (Aral and Weill 2007). Based on the second research stream discussed in Section 2.1 above, transactional IT systems will generate benefits consistent with their organisational goals. Thus, it is hypothesised that:

Hypothesis 1: Transactional IT System Quality has a positive effect on the transactional dimension of Business Value.

Based on the second research stream discussed in Section 2.1 above, informational IT systems (Aral and Weill 2007), will create informational benefits (Wixom et al. 2013) consistent with their organisational goals. Therefore, it is hypothesised that:

Hypothesis 2: Informational IT System Quality has a positive effect on the informational dimension of Business Value.

The variance in business value from the use of transactional and informational systems is also explained by the quality of the emergent IT-enabled business system. Our third hypothesis is based on systems theory and the complementarity between systems as the main driver of business value from IT. Based on systems theory, the interaction between informational and transactional IT implemented within a business system will give rise to emergent IT-enabled business systems over time with emergent properties such as competitive actions based on analytical insights that are also embedded within processes.

We explain this hypothesis using an example from a CRM business system. The interaction of transactional and informational IT systems within a CRM business system will give rise to an emergent IT-enable CRM systems with emergent properties. The emergent properties are new and extended capabilities of CRM people to take competitive actions based on insights provided by the informational system and embedded using the transactional IT system. The 
competitive actions include cross selling, up selling and targeted marketing based on the insights from customer value analysis, customer behaviour analysis and customer segmentation (Goodhue et al. 2002). The emergent IT-enabled CRM system uses the transactional IT system to collect customer data over time from many different touch points. The informational system analyses the data with different analytical tools and proposes a variety of tailored services, which can beautomated using the transactional IT system and then frequently used. This use of IT systems has transformed the role of CRM from an operational area to a strategic area for organisations to innovate, compete and gain competitive advantage (Goodhue et al. 2002). Examining the value of transactional and informational IT systems in isolation does not capture the complementary interactions or the emergent properties. The emergent IT-enabled business system includes the complementary interactions between its components. Therefore, it is capable of generating business value in addition to transactional and informational value. As a result, it is hypothesised that:

Hypothesis 3: Emergent IT-enabled business system quality has a positive effect on the strategic dimensions of business value.

\section{Discussion}

The theoretical model developed in this paper explains how transactional and informational IT systems interact to develop higher-order emergent IT-enabled business systems. Emergent IT-enabled business systems are enabled by the two IT systems and capture the complementary interactions between transactional IT and informational IT.

\subsection{Contributions to Research}

This conceptualisation has six implications for the BVIT literature.

First, organisations invest in different classes of IT system to achieve different goals. A successful implementation of one class of IT system encourages and enables organisations to invest in other classes of IT systems. Furthermore, technological advancements and competitive market conditions force managers to invest more in IT, rather than lagging behind the competition. This leads to the implementation of multiple IT asset classes in a single business unit. The BVIT literature to date has tended to examine the business value generated by one class of IT system. This underestimates the business value created from the interaction between different classes of IT system. In this paper, we conceptualise the interactions and complementary relations between two different classes of IT system and propose that the two systems together can create greater business value. This is consistent with the current competitive business environment, in which organisations invest in multiple IT systems.

Second, the relationship between IT and business value is indirect, through the mediating role of organisational processes. Transactional and informational IT systems generate business value indirectly by enabling and augmenting business unit capabilities and processes. While transactional systems are implemented in a business system to automate the processes, informational systems are implemented to informate the same processes (Zuboff, 1988). Transactional and informational systems together support more intelligent and efficient business processes. We conceptualise the indirect path using a systems approach (BurtonJ ones et al. 2014). We argue that transactional, informational and business systems together comprise a new higher-level system, in which they will complement and reinforce each other in accomplishing organisational tasks. The business unit capabilities enabled by these two interacting systems will influence the strategic dimensions of business value. The systems approach extends the literature on testing complementary relations. The current literature on complementarity measures the concepts in isolation and brings them together as a statistical interaction effect (Aral and Weill 2007; Titah and Barki 2009). In contrast, using the systems approach, we conceptualise the interactions among the systems and their emergent properties, which may not be captured using statistical approaches. This extends the RBV and complementarity (Aral and Weill 2007) literature as well as enriching the fit concept (Venkatraman 1989) and the theory of task-technology fit (Goodhue and Thompson 1995). 
Third, we argue that multiple IT systems interact with other business systems and higher-level emergent IT-enabled business systems emerge from their interaction. Based on systems theory, the evolution of systems and the emergence of new systems is a socially complex process. Therefore, emergent IT-enabled business systems satisfy the VRIN properties of RBV theory in terms of having path dependencies, causal ambiguity and a complex social structure (Bharadwaj 2000b). Therefore, emergent IT-enabled business systems are capable of creating significant business value and contributing to competitive advantage. On the other hand, each system in our research model includes assets as well as capabilities. This signifies that technological assets alone are not a source of value. However, complementarity and synergy between IT capabilities and IT assets are important in creating value.

Fourth, multilevel approaches to theory and research seek causal explanations for emergence in organisational contexts. We use complementarity as the underlying phenomenon that explains the emergence of higher-order IT-enabled systems. The positive emergent properties are a source of significant benefits for organisations.

Fifth, our research model also helps to theorise about the business value generated from informational IT systems (such as BA systems). In recent years, several theoretical models have been proposed to explain how value is created from BA systems (Davenport and Harris 2007; Davenport et al. 2010; Elbashir et al. 2008; Isik et al. 2011; Shanks and Bekmamedova 2012; Sharma et al. 2010; Wixom and Watson 2001; Wixom et al. 2013). None of these models considers the interaction of BA systems and other organizational systems. Our study describes how informational IT systems can interact with other organizational systems to generate business value. This is important because informational IT systems are strategic investments for many organisations.

Sixth, within RBV, organisations are conceptualised as collections of resources (Barney 1991). Although RBV theory has successfully helped researchers to establish a link between IT resources and business value, it does not model the interactions among resources. Hence, the interactions among resources have been addressed in the BVIT literature only to a limited extent. The use of other theoretical lenses such as systems theory in addition to RBV theory can help mitigate this problem.

\subsection{Contributions to Practice}

For practitioners, the research model provides a means of understanding the importance of complementary relations between different IT systems and the emergence of new IT-enabled business systems. This understanding will effect manager's IT investment decisions in choosing systems that will complement their current IT systems. It also signifies the importance of bringing the systems together and facilitating complementary interactions among them to embed IT in business processes, generate business value and gain competitive advantage. The research model helps to conceptualise the business value of informational IT systems, which is important in justifying the huge investments in these systems.

\subsection{Future Research Directions}

We have proposed a model that explains how two classes of IT system can together create ITbased business value for organisations. Our conceptualisation implies that having two separate high-quality systems is associated with limited benefits and is not necessarily a driver of business value. However, how the two systems work together, complement each other and have synergy, is critical in leveraging the IT systems and creating IT-based business value (Asadi Someh and Shanks 2013a, 2013b). Understanding the underlying mechanisms that realise synergy between IT and other business systems is an important research direction. Also we have proposed three testable research hypotheses for benefits from transactional IT and informational IT systems in isolation and together within emergent IT-enabled business systems. Empirical confirmation and refinement of the research model is an important research direction to follow. We will design and conduct a survey to collect data in the CRM area to test the three hypotheses. Since there is a time lag between implementing IT systems 
and achieving the benefits at firm level, a longitudinal study is another avenue for future research.

\section{Conclusion}

The objective of our study was to examine how two classes of IT systems, namely transactional and informational systems, interact to augment business processes and create business value. We used systems theory and the concept of emergence to propose a new research model. The model argues that transactional and informational IT systems individually create transactional and informational benefits. Emergent IT-enabled business systems capturing the complementary interactions between transactional IT and informational IT will create strategic benefits in addition to the benefits created by the individual systems. Further empirical assessment of the research model is encouraged for future research.

\section{References}

Ackoff, R. L. 1971. “Towards a System of Systems Concepts,” Management Science (17:11), pp. 661- 671.

Aral, S., and Weill, P. 2007. "IT Assets, Organizational Capabilities, and Firm Performance: How Resource Allocations and Organizational Differences Explain Performance Variation," Organization Science (18:5), pp. 763- 780.

Asadi Someh, I., and Shanks, G. 2013a. "The Role of Synergy in Achieving Value from Business Analytics Systems," in International Conference on Information Systems (ICIS), Milan, Italy.

Asadi Someh, I., and Shanks, G. 2013b. "Realising Synergy in Business Analytics Enabled Systems," in 24th Australasian Conference on Information Systems, Melbourne, p. paper 251.

Barney, J. 1991. "Firm Resources and Sustained Competitive Advantage," Journal of Management (17:1), p. 99.

Bharadwaj, A. 2000a. "A Resource-based Perspective on Information Technology Capability and Firm Performance: An Empirical Investigation," MIS Quarterly (24:1), pp. 169- 196.

Bharadwaj, A. 2000b. "A Resource-Based Perspective on Information Technology Capability and Firm Performance: An Empirical Investigation," MIS Quarterly (24:1), p. 169 (doi: 10.2307/3250983).

Broadbent, M., Weill, P., and Neo, B. 1999. "Strategic context and patterns of IT infrastructure capability," The J ournal of Strategic Information ... (8 December 1996), pp. 157- 187.

Brynjolfsson, E. 1993. "The productivity paradox of information technology," Communications of the ACM (36:12), pp. 66- 77.

Burton-jones, A., Mclean, E. R., and Monod, E. 2014. "Theoretical perspectives in IS research : from variance and process to conceptual latitude and conceptual fit," European J ournal of Information Systems, pp. 1- 16.

Buttle, F. 2004. Customer Relationship Management : Concepts and Tools, Oxford: Elsevier Butterworth-Heinemann.

Carr, N. G. 2003. “TT doesn’t matter,” Harvard Business Review (81:5), New York, pp. 41-49, 128.

Chae, H., Koh, C., and Prybutok, V. 2014. "Information Technology Capability and Firm Performance: Contradictory Findings and Their Possible Causes," MIS Quarterly (38:1), pp. 305- 326.

Chen, H., Chiang, R., and Storey, V. 2012. "Business Intelligence and Analytics: From Big Data to Big Impact," MIS Quarterly (36:4), pp. 1165- 1188. 
Coltman, T. 2007. 'Why build a customer relationship management capability?," The J ournal of Strategic Information Systems (16:3), pp. 301- 320.

Corning, P. A. 2002. "The re-emergence of emergence: A venerable concept in search of a theory," Complexity (7:6), pp. 18-30.

Davenport, T. H., and Harris, J. G. 2007. Competing on Analytics: The New Science of Winning, Harvard Business School Press.

Davenport, T. H., Harris, J . G., and Morison, R. 2010. Analytics at Work: Smarter Decisions, Better Results, Cambridge, MA: Harvard Business School Press.

Elbashir, M. Z., Collier, P. a., and Davern, M. J. 2008. "Measuring the effects of business intelligence systems: The relationship between business process and organizational performance," International Journal of Accounting Information Systems (9:3), pp. 135- 153.

Goodhue, D. L., and Thompson, R. L. 1995. "Task-Technology Fit and Individual Performance," MIS Quarterly (19:2), p. 213 (doi: 10.2307/249689).

Goodhue, D., Wixom, B., and Watson, H. 2002. "Realizing business benefits through CRM: hitting the right target in the right way," MIS Quarterly Executive (1:2).

Hagerty, J ., Sallam, R. L., and Richardson, J . 2012. “Magic Quadrant for Business Intelligence Platforms," Gartner document.

IBM. 2013. “The 2012 IBM Tech Trends Report,” (available at https:// www.ibm.com/ developerworks/community/ blogs/ techtrends/ entry/ byindustr y?lang=en).

Iriana, R., and Buttle, F. 2006. "Strategic, operational, and analytical customer relationship management: attributes and measures," J ournal of Relationship Marketing (5:4).

Isik, O., J ones, M., and Sidorova, A. 2011. "Business Intelligence (BI) Success and the Role of BI Capabilities," Intelligent Systems in Accounting, Financeand Management (176), pp. 161- 176.

Kast, F. E., and Rosenzweig, J . E. 1981. "General systems theory: applications for organization and management," Academy of Management J ournal (11:7), pp. 32- 41.

Kohli, R. 2008. "Business value of IT: An essay on expanding research directions to keep up with the times," J ournal of the Association for Information (9:1), pp. 23- 39.

LaValle, S., and Lesser, E. 2013. "Big data, analytics and the path from insights to value," MIT Sloan Management Review.

Lucas, H. 1999. Information Technology and the Productivity Paradox: Assessing the Value of Investing in IT (Google eBook), Oxford University Press.

Melville, N., Kraemer, K., and Gurbaxani, V. 2004. “Review: Information Technology and Organizational Performance: An Integrative Model of IT Business Value," MIS Quarterly (28:2), pp. 283- 322.

Mithas, S., Ramasubbu, N., and Sambamurthy, V. 2011. "How Information Management Capability Influences Firm Performance," MIS Quarterly (35:1), pp. 237- 256.

Mithas, S., Tafti, A., Bardhan, I., and Goh, J. M. 2012. "Information Technology and Firm Profitability: Mechanisms and Empirical Evidence," MIS Quarterly (36:1), pp. 205- 224.

Nevo, S., and Wade, M. 2010. "The Formation and Value of IT-enabled Resources: Antecedents and Consequences of Synergistic Relationships," MIS Quarterly (34:1), pp. 163- 183.

Nevo, S., and Wade, M. 2011. "Firm-Level Benefits of IT-enabled Resources: A Conceptual Extension and an Empirical Assessment," The J ournal of Strategic Information Systems (20:4), pp. 403-418. 
Pang, M.-S., Lee, G., and DeLone, W. H. 2014. "In public sector organisations: a public-value management perspective,”J ournal of Information Technology (29:3), pp. 187- 205.

Pavlou, P. a., and El Sawy, O. a. 2006. "From IT Leveraging Competence to Competitive Advantage in Turbulent Environments: The Case of New Product Development," Information Systems Research (17:3), pp. 198- 227.

Penrose, E. T. 1995. The Theory of the Growth of the Firm, NewYork: Oxford University Press.

Ray, G., Muhanna, W., and Barney, J . 2005. "Information technology and the performance of the customer service process: A resource-based analysis," MIS Quarterly (29:4), pp. 625- 652 (available at http:/ / www.jstor.org/ stable/ 25148703).

Santhanam, R., and Hartono, E. 2003. "Issues in linking information technology capability to firm performance," MIS Quarterly (27:1), pp. 125-153 (available at http:// www.jstor.org/ stable/ 30036521).

Shanks, G., and Bekmamedova, N. 2012. "Achieving Benefits with Business Analytics Systems: An Evolutionary Process Perspective," J ournal of Decision Systems (3:November), pp. 37-41.

Sharma, R., Reynolds, P., Scheepers, R., Seddon, P. B., and Shanks, G. 2010. "Business Analytics and Competitive Advantage: A Review and a Research Agenda," in Bridging the Socio-technical Gap in Decision Support Systems: Challenges for the Next Decade, , August 1, pp. 187- 198.

Tanriverdi, H. 2005. "Information Technology Relatedness, Knowledge Management Capability, and Performance of Multibusiness Firms," MIS Quarterly (29:2), pp. 311334.

Tanriverdi, H. 2006. "Performance Effects of Information Technology Synergies in Multibusiness Firms," MIS Quarterly (30:1), pp. 57- 77.

Titah, R., and Barki, H. 2009. "Nonlinearities between Attitude and Subjective Norms in Information Technology Acceptance: A Negative Synergy?,” MIS Quarterly (33:4), pp. 827-844.

Venkatraman, N. 1989. "The concept of fit in strategy research: toward verbal and statistical correspondence," Academy of Management Review (14:3), pp. 423- 444.

Weill, P. 1992. "The relationship between investment in information technology and firm performance: a study of the valve manufacturing sector," Information Systems Research (239).

Weill, P., and Olson, M. 1989. "An assessment of the contingency theory of management information systems," J ournal of Management Information Systems (6:1), pp. 59- 85.

Wixom, B., and Watson, H. 2001. "An Empirical Investigation of the Factors Affecting Data Warehousing Success," MIS Quarterly (25:1), pp. 17- 41.

Wixom, B., Yen, B., and Relich, M. 2013. "Maximizing Value from Business Analytics," MIS Quarterly Executive (2013: J une), pp. 61- 71.

Zuboff S. 1988. In theAge of the Smart Machine: The Future of Work and Power. Basic Books, New York.

Copyright: (C) 2016 Asadi Someh, Shanks. This is an open-access article distributed under the terms of the Creative Commons Attribution-NonCommercial 3.0 Australia License, which permits non-commercial use, distribution, and reproduction in any medium, provided the original author and AJ IS are credited. 


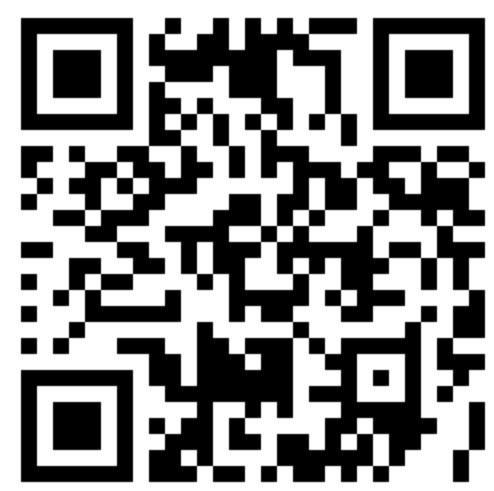

